\title{
NONLINEAR INTEGRAL INEQUALITY IN TWO INDEPENDENT VARIABLES
}

\author{
P.T. VAZ and S.G. DEO \\ Department of Mathematics \\ University Goa \\ Bambolim, Goa - 403001 \\ INDIA
}

(Received May 27, 1986 and in revised form October 28, 1986)

ABSTRACT. In this note, the authors obtain a generalization of the integral inequality of Bihari [1] to a nonlinear inequality in two independent variables. With the aid of this inequality a bound for the solution of a nonlinear partial differential equation is established.

KEYS WORDS AND PHRASES. Nonlinear integral inequality, submultiplicative function, nonlinear partial differential equation.

1980 AMS SUBJECT CLASSIFICATION CODE. Primary 35R45, Secondary 34 A40.

1. INTRODUCTION.

In the qualitative analysis of differential equations integral inequalities play a vital role [2]. An inequality due to Gronwall continues to draw the attention of mathematicians because of its usefulness. The nonlinear generalization of this inequality due to Bihari [1] is as follows:

LEMMA 1. Let $Y(x), F(x)$ be positive continuous functions in $a \leqq x \leqq b$ and $K \geqq o, M \geqq o$, further $W(u)$ a non-negative non-decreasing continuous function for $\mathrm{u} \geqq$ o. Then the inequality

$$
Y(x) \leqq K+M \int_{a}^{x} F(t) \quad W(Y(t)) d t \quad(a \leqq x \leqq b)
$$

implies the inequality

$$
Y(x) \leqq G^{-1}\left(G(K)+M \int_{a}^{x} F(t) d t\right) \quad\left(a \leqq x \leqq b^{\prime} \leqq b\right)
$$

where

$$
G(u)=\int_{u_{0}}^{u} \frac{d t}{W(t)} \quad\left(u_{0}>0, u \geq 0\right) .
$$

This inequality has been further generalized in several directions by Beesack [3].

It has been recently established that the inequalities of this type in two and more independent variables can be profitably employed in the analysis of partial differential equations [4, and references 1isted therein]. An interesting inequality by Wendroff given without proof in [5] is as follows: 
LEMMA 2. Let $\mathrm{J}=\{\mathrm{x} \mid \mathrm{o} \leqq \mathrm{x} \leqq \mathrm{X}<\infty\}$ and $\mathrm{K}=\{\mathrm{y} \mid \mathrm{o} \leqq \mathrm{y} \leqq \mathrm{Y}<\infty\}$. Further let $\mathrm{U}(\mathrm{x}, \mathrm{y})$ be a scalar, non-negative continuous function defined on $\mathrm{J} x \mathrm{~K}$, then for any arbitrary non-negative constants $a, b$ and $c$, the integral inequality

$$
U(x, y) \leqq c+a \int_{0}^{x} U(s, y) d s+b \int_{0}^{y} U(x, t) d t
$$

implies that $U(x, y) \leqq c \exp (a x+b y+a b x y)$.

The proof of this inequality can be constructed by observing that $U \leqq P$, where $P(x, y)$ satisfies the equation

$$
P(x, y)=c+a \int_{0}^{x} P(s, y) d s+b \int_{0}^{y} P(x, t) d t .
$$

Observe that $\mathrm{P}(\mathrm{x}, \mathrm{o})=\mathrm{c} \exp (\mathrm{ax})$ and $\mathrm{P}(\mathrm{o}, \mathrm{y})=\mathrm{c} \exp (\mathrm{by})$. Now assuming $P(x, y)=\exp (a x+b y) q(x, y)$, one can determine the inequality satisfied by $q(x, y)$ which results into the given conclusion.

Lemma 2, in view of Lemma 1, suggests that it is possible to consider a nonlinear generalization of the Wendroff's inequality. We do this in the present paper and further show by an example that the generalization of this kind is truely beneficial in the study of some nonlinear partial differential equations.

2. NOTATION.

Let $\mathbb{R}$ denote the real line. For any rectangle $\mathrm{J} \times \mathrm{K}$ we define the following classes of functions:

(i) $\mathrm{C}^{+}(\mathrm{JxK})=$ the space of continuous functions $\mathrm{u}: \mathrm{J} \times \mathrm{K} \rightarrow \mathbb{R}^{+}$

(ii) $C_{1}\left(\mathbb{R}^{+}\right)$= the space of non-decreasing, non-negative, submultiplicative, continuous functions on $\mathbb{R}^{+}$.

(iii) $\mathrm{C}_{2}\left(\mathbb{R}^{+}\right)=$the space of non-decreasing, non-negative, continuous functions on $\mathbb{R}^{+}$and such that for $g_{2} \in C_{2}\left(\mathbb{R}^{+}\right)$and for any real-valued function $h(x, y),(x, y) \in J \times K$,

$$
\frac{g_{2}(u(x, y))}{h(x, y)} \leqq g_{2}\left(\frac{u(x, y)}{h(x, y)}\right), \quad h(x, y) \geqq 1 .
$$

Further, we define

$$
G_{i}(u)=\int_{u_{0}}^{u} \frac{d t}{g_{i}(t)}, \quad\left(u \geqq 0, u_{0}>0\right) .
$$

Let $G_{i}^{-1}$ be the inverse of $G_{i}, i=1,2$.

3. MAIN RESULT.

THEOREM 3.1. Assume that

$$
\begin{aligned}
& \text { (a) } u(x, y) \in C^{+}(J \times K), \\
& \text { (b) } g_{1}(u) \in C_{1}\left(\mathbb{R}^{+}\right) \text {, } \\
& \text { (c) } g_{2}(u) \in C_{2}\left(\mathbb{R}^{+}\right) \text {, } \\
& \text { (d) there exists a } u_{0}>0 \text { such that } g_{1}(u)>0 \text { and } g_{2}(u)>o \text { for }
\end{aligned}
$$
$u \geqq u_{o}$. Then for any arbitrary non-negative constants $a, b$ and $c$, with $c \geqq 1$, the inequality 


$$
u(x, y) \leqq c+a \int_{0}^{x} z_{1}\left(u(s, y) d s+b \int_{0}^{y} g_{2}(u(x, t)) d t, \quad(0 \leqq x \leqq x, 0 \leqq y \leqq y)\right.
$$

implies, on a nonempty rectangle, the inequality

$$
u(x, y) \leqq G_{1}^{-1}\left\{G_{1}(c)+\operatorname{axg}_{1}\left[G_{2}^{-1}\left(G_{2}(1)+b y\right)\right]\right\} g_{2}^{-1}\left(G_{2}(1)+b y\right),
$$

where $G_{i}(u), i=1,2$, are as defined in $(2.2),\left(0 \leqq x \leqq X^{\prime} \leqq X\right.$ and $\left.0 \leqq y \leqq Y^{\prime} \leqq Y\right)$. PROOF. We define

$$
h(x, y)=c+a \int_{0}^{x} g_{1}(u(s, y)) d s,(x, y) \in J x k .
$$

It is clear that $\mathrm{h}(\mathrm{x}, \mathrm{y})$ is non-decreasing and $\mathrm{h}(\mathrm{x}, \mathrm{y}) \geqq 1$ on $\mathrm{J} \mathrm{x}$. Inequality (3.1) may be written as

$$
u(x, y) \leqq h(x, y)+b \int_{0}^{y} g_{2}(u(x, t)) d t .
$$

Dividing throughout by $h(x, y)$ and using (2.1) of assumption (c) we have

$$
\frac{u(x, y)}{h(x, y)} \leqq 1+b \int_{0}^{y} g_{2}\left(\frac{u(x, t)}{h(x, t)}\right) d t .
$$

For fixed $x \in J$, an application of Lemma 1 yields

$$
u(x, y) \leqq h(x, y) \cdot G_{2}^{-1}\left(G_{2}(1)+b y\right), \quad\left(0 \leqq x \leqq x, o \leqq y \leqq Y^{\prime} \leqq Y\right)
$$

Substituting (3.6) in (3.3) and employing submultiplicative property of $g_{1}$ we obtain

$$
h(x, y) \leqq c+a \int_{0}^{x} g_{1}(h(s, y)) g_{1}\left(G_{2}^{-1}\left(G_{2}(1)+b y\right)\right) d s .
$$

An application of Lemma 1 again, to (3.7), yields a bound for $h(x, y)$ on a nonempty rectangle. The desired inequality now follows by substituting the bound for $\mathrm{h}(\mathrm{x}, \mathrm{y})$ in $(3.6)$.

REMARK 3.1. In particular, if $b=0$ and $g_{1}(u)=u$, then the estimate in (3.2) reduces to

$$
u(x, y) \leqq G_{1}^{-1}\left[G_{1}(c)+a x\right]
$$

In view of (2.2), it is clear that for fixed $y \in K$, our estimate further reduces to

$$
u(x, y) \leqq c \exp (a x)
$$

Thus, Gronwall's estimate is included in (3.2).

REMARK 3.2. In the case $b=0$, the estimate in (3.2) reduces to

$$
u(x, y) \leqq G_{1}^{-1}\left[G_{1}(c)+a x g_{1}(1)\right]
$$

for each $y \in K, 0 \leqq x \leqq X^{\prime} \leqq X$, which is a Bihari-like estimate.

Further, if in (3.1), $a=0$, then for fixed $x \in J$,

$$
u(x, y) \leqq c+b \int_{0}^{y} g_{2}(u(x, t)) d t
$$


implies

$$
\frac{u(x, y)}{c} \leq 1+b \int_{o}^{y} g_{2}\left(\frac{u(x, t)}{c}\right) d t, \quad y \in K .
$$

An application of Lemma 1 yields

$$
\begin{aligned}
u(x, y) & \leq \mathrm{c}_{2}^{-1}\left[\mathrm{G}_{2}(1)+b y\right], \\
& \left(\mathrm{x} \in \mathrm{J} \text { is fixed, } \mathrm{o} \leq \mathrm{y} \leq \mathrm{Y}^{\prime} \leq \mathrm{Y}\right)
\end{aligned}
$$

This estimate is the same as that obtained from (3.2) with $a=0$.

REMARK 3.3. Let $g_{i}(u)=u, i=1,2$. Then

$$
G_{i}(u)=\log \frac{u}{u o}, u \geq 0, u_{o}>0, i=1,2 \text {. }
$$

Clearly

$$
G_{i}^{-1}(v)=u_{0} \exp (v), \quad i=1,2 .
$$

Hence the estimate $(3.2)$ reduces to

$$
\begin{aligned}
u(x, y) & \leq u_{o} \exp \left[\log \frac{c}{u_{o}}+a x u_{o} \exp \left(\log \frac{1}{u_{o}}+b y\right)\right] \cdot u_{o} \exp \left(\log \frac{1}{u_{o}}+b y\right) \\
& \leq c \exp [a x \exp (b y)+b y] \\
& =c \exp [a x+b y+a b x y+\text { higher order terms }] .
\end{aligned}
$$

This estimate is obviously not as sharp as the one obtained in Lemma 2 .

4. AN APPLICATION.

Consider the characteristic initial value problem for the nonlinear partial differential equation

$$
\begin{array}{r}
u_{x y}=u^{a} u_{y}+b e u_{x}, \quad a, b \geq 0, \\
(0 \leq x \leq x, \quad 0 \leq y \leq Y)
\end{array}
$$

satisfying the initial values

$$
\mathrm{u}(\mathrm{x}, \mathrm{o})=\mathrm{u}(0, \mathrm{y})=\mathrm{u}(0, \mathrm{o})=\mathrm{c} \geq 1
$$

Under the condition (4.2) equation (4.1) can be reformulated in terms of the integral equation

$$
\begin{array}{r}
u(x, y)=c-\frac{1}{a+1} \int_{0}^{x} u^{a+1}(s, o) d s-b \int_{0}^{x} e^{u(o, t)} d t \\
+\frac{1}{a+1} \int_{0}^{y} u^{a+1}(s, y) d s+b \int_{0}^{y} e^{u(x, t)} d t .
\end{array}
$$

Therefore, using the initial - data, we obtain the inequality

$$
|u(x, y)| \leq k+\frac{1}{a+1} \int_{0}^{x}|u(s, y)|^{a+1} d s+b \int_{o}^{y} e^{|u(x, t)|} d t,
$$

where $k=\left(|c|+\frac{|c|^{a+1} X}{a+1}+b e^{|c|}\right)$. 
The present inequality is equivalent to (3.1). A direct application of Theorem 3.1 yields

$$
|u(x, y)| \leq G_{1}^{-1}\left[G_{1}(k)+\frac{x}{a+1}\left[G_{2}^{-1}\left(G_{2}(1)+b y\right)\right]^{a+1}\right] \cdot G_{2}^{-1}\left(G_{2}(1)+b y\right)
$$

where

$$
G_{1}(u)=\int_{0}^{u} \frac{1}{p^{a+1}} d p=-\frac{1}{a}\left[\frac{1}{u^{a}}-\frac{1}{u_{0}^{a}}\right] \text {, and } G_{2}(u)=\int_{0}^{u} \frac{1}{e^{p}} d p=-\left[e^{-u}-e^{-u_{0}}\right] .
$$

Therefore,

$$
G_{1}^{-1}(v)=\left[u_{o}^{-a}-a v\right]^{-1 / a} \text { and } G_{2}^{-1}(v)=\log _{e}\left[e^{-u_{o}}-v\right]^{-1} \text {. }
$$

Hence,

$$
|u(x, y)| \leq\left\{k^{-a}-\frac{a x}{a+1}\left[\log \left(e^{-1}-b y\right)^{-1}\right]^{a+1}\right\}^{-1 / a} \cdot \log \left(e^{-1}-b y\right)^{-1} .
$$

This provides a pointwise estimate for solutions of the given equation (4.1).

REFERENCES

1. BIHARI, I. A Generalization of a Lemma of Bellman and Its Application to Uniqueness Problems of Differential Equations, Acta Math. Acad. Sc1. Hungar. 7 (1956), 71-94.

2. LAKSHMIKANTHAM, $\mathrm{V}$. and LEELA, S. Differential and Integral Inequalities, Theory and Applications, Vol. I, Academic Press, New York, 1969.

3. BEESACK, P.R. On Integral Inequalities of Bihari Type, Acta Math. Acad. Sci. Hungar. 28 (1976), 81-88.

4. CORDUNEANU, A. A Note on the Gronwall Inequality in Two Independent Variables, Journal of Integral Equations 4 (1982), 272-276.

5. BECKEMBACK, E.F. and BELLMAN, R. Inequalities, Springer-Verlag, Berlin, 1961. 


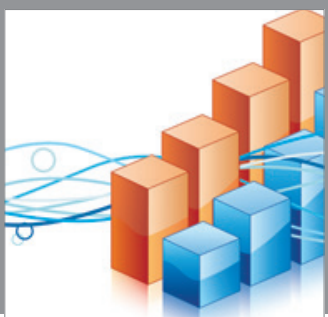

Advances in

Operations Research

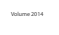

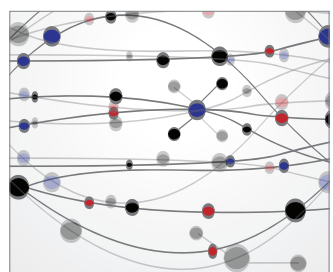

\section{The Scientific} World Journal
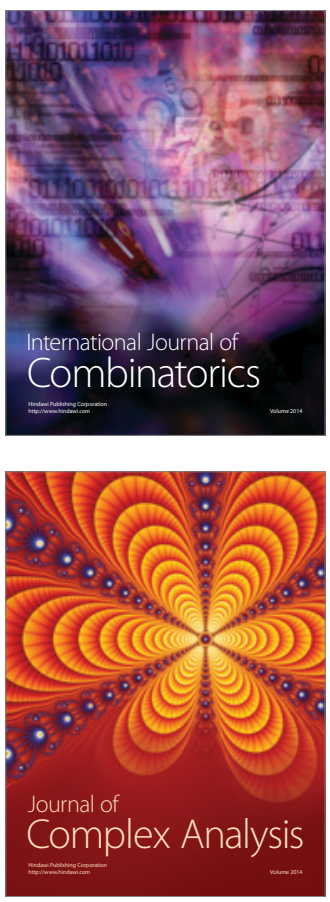

International Journal of

Mathematics and

Mathematical

Sciences
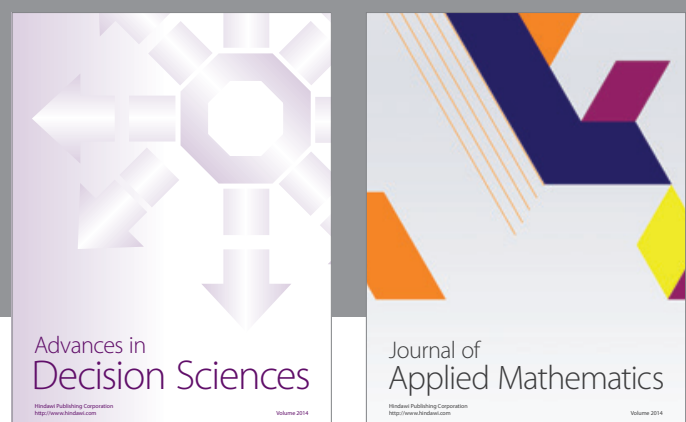

Journal of

Applied Mathematics
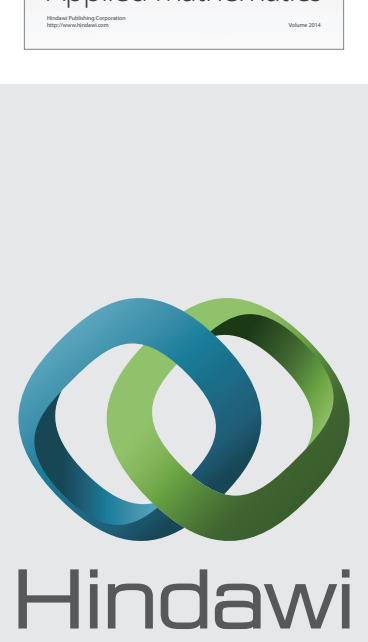

Submit your manuscripts at http://www.hindawi.com
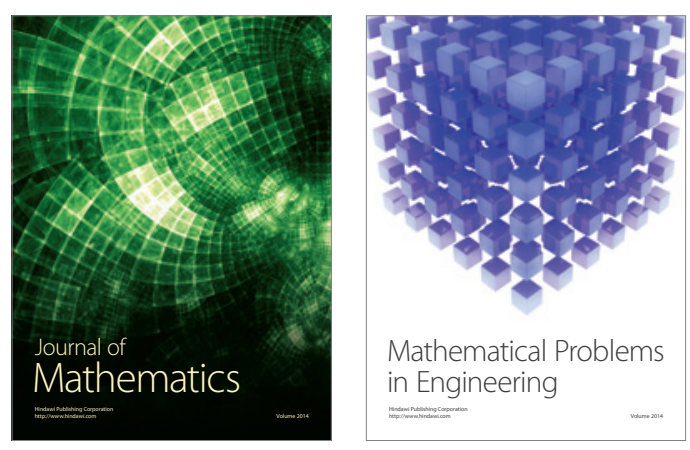

Mathematical Problems in Engineering
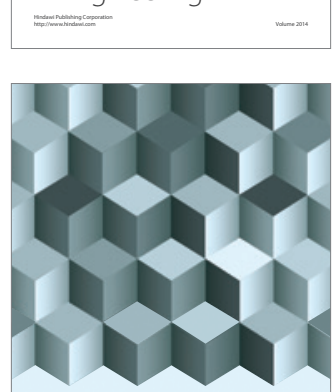

Journal of

Function Spaces
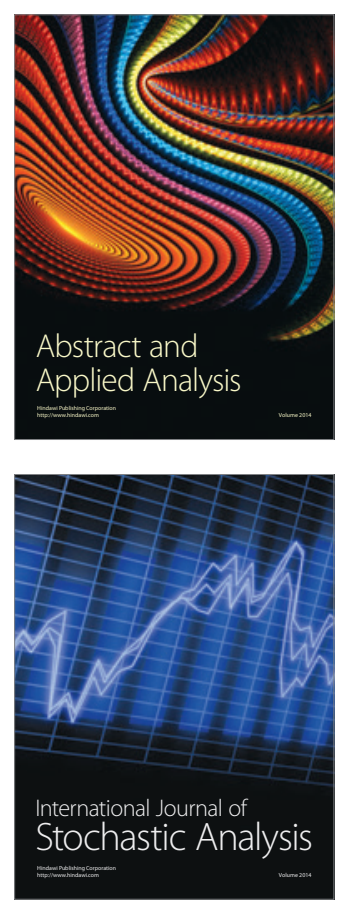

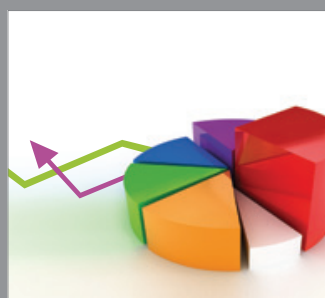

ournal of

Probability and Statistics

Promensencen
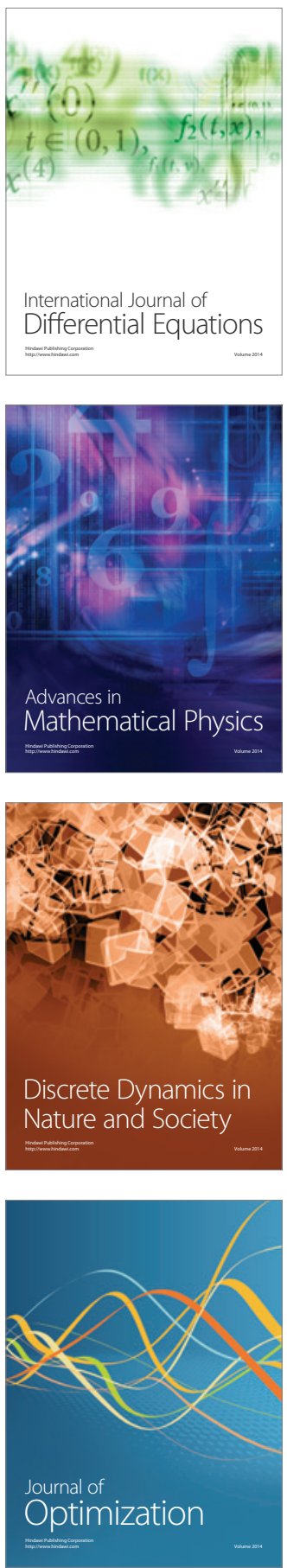